\title{
PERSOALAN STATUS SEBAGAI ANAK-ANAK ABRAHAM \\ DALAM SURAT GALATIA
}

\section{Samuel Benyamin HakH*}

\begin{abstract}
In the apostle Paul's letter to the Galatians, one of the principal theological debate sticking to the surface is the status as children of Abraham through circumcision. Because according to a group of Jews Christian who came to Galatia, Gentile Christians shall be circumcised, and implement the law, if they want to obtain salvation. Because safety is only given to those who become the children of Abraham in full.

On the other hand, Paul rejected that obligation. According to Paul, by faith in Christ, the son of Abraham, Christians in Galatia, having status as the children of Abraham and inherit the blessings of God's promise that is salvation. In this article I argue that the debate was due on the one hand, Jewish Christian groups that cling to the tradition of circumcision because of the tradition that has been in effect since Abraham and believed to be the way of salvation, while Paul emphasis on faith and obey the decision of the council in Jerusalem that circumcision is not required for the non-Jewish.
\end{abstract}

Keywords: Abraam, circumcision, faith, gospel, grace, justification, law, offspring, sons of Abraham, status.

\section{Abstrak}

Dalam surat Rasul Paulus kepada jemaat di Galatia, salah satu pokok perdebatan teologis sosiologis yang mencuat ke permukaan adalah status sebagai anak-anak Abraham melalui

* Ketua Badan Penjaminan Mutu Sekolah Tinggi Teologi Jakarta hingga 2018. Doktor Teologi (D. Th.) dari STT Jakarta, bidang Perjanjian Baru. Email: samuelbenyamin@ymail.com. 
sunat. Sebab menurut kelompok orang Kristen Yahudi yang datang ke Galatia, orang Kristen non-Yahudi wajib disunat dan melaksanakan hukum Taurat, jika mereka ingin beroleh selamat. Sebab keselamatan hanya diberikan kepada orang-orang yang menjadi anak-anak Abraham secara penuh.

Di pihak lain, Paulus menolak kewajiban itu. Menurut Paulus, oleh iman di dalam Kristus, anak Abraham itu, orang Kristen di Galatia telah beroleh status sebagai anak-anak Abraham dan mewarisi janji berkat Allah itu, yakni keselamatan. Dalam artikel ini saya berargumentasi bahwa perdebatan itu terjadi karena pada satu pihak, kelompok Yahudi itu berpegang teguh kepada tradisi sunat karena tradisi itu telah diberlakukan sejak Abraham dan diyakini sebagai jalan keselamatan, sementara Paulus menekankan pada iman serta taat kepada keputusan sidang di Yerusalem bahwa sunat tidak diwajibkan bagi orang nonYahudi.

Kata-kata kunci: Abraham, sunat, iman, Injil, anugerah, pembenaran, Taurat, keturunan, anak-anak Abraham, status.

\section{PENDAHULUAN}

Secara sosiologis orang-orang Yahudi memandang Abraham sebagai bapa leluhur bangsa Israel dan mereka memiliki status sebagai "tunas" atau "anak-anak Abraham". Orang-orang nonYahudi bisa memperoleh status itu jika mereka melakukan empat syarat, yakni: melaksanakan Taurat, disunat, dibaptis, dan mempersembahkan korban. ${ }^{1}$ Status itu merupakan suatu tanda yang membedakan mereka sebagai bangsa pilihan Allah dengan bangsa-bangsa lain, karena Allah telah memilih mereka sebagai umat pilihan (Ps. Sol. 9:8-9) dan pewaris janji-Nya (Sir. 44:21).

Status ini dipakai juga oleh Rasul Paulus, lalu dikenakan kepada orang Kristen sebagai “anak-anak Abraham” (Baird, 1988: 368, 369). Namun Paulus menolak sunat dan hukum Taurat sebagai syarat memperoleh status itu. Menurut Paulus orang-orang Kristen non-Yahudi tidak perlu disunat sebab sunat merupakan tradisi Yahudi saja dan tradisi itu dikenakan kepada setiap orang yang mau masuk menjadi proselit Yahudi. Persoalannya adalah, apakah setiap orang harus masuk menjadi proselit Yahudi barulah memperoleh status sebagai anak-anak Abraham dan beroleh selamat? Menurut Paulus, iman itu menjadi jaminan bagi setiap orang untuk memperoleh status sebagai anak Abraham itu (Gal. 3:7). Oleh sebab itu, orang non-Yahudi yang masuk Kristen tidak perlu menjadi proselit 
melalui sunat dan melaksanakan hukum Taurat. Perbedaan pandangan inilah yang menyebabkan perdebatan antara "lawan-lawan Paulus" yang datang ke Galatia itu dengan Rasul Paulus.

Paulus menyebut lawan-lawannya itu sebagai "saudara-saudara palsu” (Gal. 2:4) dan orang-orang yang "menyunatkan diri" tetapi tidak memelihara hukum Taurat (Gal. 6:13). Sapaan pertama adalah: "saudara-saudara palsu" menunjukkan bahwa lawan-lawan Paulus itu adalah orang Kristen. Namun mereka mendesak agar orang non-Yahudi yang masuk Kristen harus disunat maka tentu mereka adalah orang Yahudi. Dengan demikian, lawan-lawan Paulus itu adalah orang-orang Kristen Yahudi (Hakh, 2010: 173, 174; Ioanes Rakhmat, 2009: 145, 146). Mereka disebut "saudara-saudara palsu" karena mereka memberitakan "injil lain" (heteron euanggelion) yang "bukan injil” (Gal. 1:6,7). Mereka juga menuduh Paulus sebagai pengkhianat dan menentang Injil yang Paulus beritakan. Kelompok orang Yahudi Kristen ini datang ke Galatia dan menyampaikan argumentasi melawan Paulus serta mendesak jemaat untuk disunat dan melaksanakan hukum Taurat.

\section{DESAKAN AGAR ORANG KRISTEN DI GALATIA DISUNAT}

Bertolak dari perjanjian antara Allah dan Abraham tentang sunat dalam Kejadian 17:9-14 maka kelompok orang Yahudi itu menyatakan bahwa setiap orang laki-laki dari keturunan Abraham harus disunat sebagai tanda perjanjian. Demikian pula setiap hamba laki-laki yang dibeli juga harus disunat. Itulah sebabnya, tidak hanya Ishak yang lahir dari Sarah yang disunat, melainkan juga Ismael yang lahir dari Hagar (Kej. 17: 20-21). Jadi, semua anak-anak Abraham, baik merdeka maupun hamba harus disunat (Crossan dan Reed, 2004: 223, 224).

Dengan demikian, orang Galatia yang mau menjadi anak-anak Abraham, harus disunat juga. Sebab sunat, sebagai tanda perjanjian, adalah syarat untuk menjadi anak-anak Abraham secara penuh dan pewaris janji Allah kepada Abraham (Guthrie, 1973: 95). Mereka tidak cukup dibaptis menjadi orang Kristen, melainkan juga harus disunat dan melaksanakan seluruh tuntutan hukum Taurat. Mereka menuduh Paulus sebagai seorang pengkhianat (Thielman, 2005: 265). Oleh sebab itu, kelompok orang Yahudi itu datang ke Galatia untuk menyempurnakan status orang Kristen Galatia sebagai anak-anak Abraham. Demi penyempurnaan itu, mereka harus menjadi proselit dengan melakukan perjanjian sunat yang Allah perintahkan kepada Abraham. Konsekuensinya, orang Kristen di Galatia didesak menerima sunat dan melaksanakan Taurat (Matera, 2007: 152, 153), dengan maksud agar mereka menjadi anak-anak Abraham secara penuh (Longenecker, 1990: 109). 
Menurut E.P. Sanders, argumentasi kelompok orang Yahudi itu cukup beralasan, terutama jika dilihat dari sisi PL. Teks PL yang menjadi alasan yang kuat adalah Kejadian 17:9-14. Di situ, Allah memberitahukan kepada Abraham supaya ia dan keturunannya harus disunat sebab setiap orang laki-laki yang tidak disunat akan dihukum mati. Demikian juga, menurut Yesaya 56:68, orang asing yang menggabungkan diri dengan umat Allah diharapkan melakukan perjanjian (sunat), terutama memelihara hari sabat (Sanders, 1983: 18). Pandangan yang sama disampaikan juga oleh James D.G. Dunn. Menurut Dunn, kelompok orang Yahudi itu percaya bahwa Allah telah membuat perjanjian khusus dengan para leluhur mereka, sehingga mereka menjadi umat perjanjian (U1. 4:31; 2 Makk. 8:15; Amsal Sol. 9:10), Allah juga telah memberikan hukum Taurat sebagai bagian integral dari perjanjian itu agar mereka hidup menurut hukum itu (U1. 4:1,10,40; 5:29-33; 6:1-2, 18,24). Lebih jauh, Dunn mengatakan bahwa salah satu faktor utama mengapa orang Yahudi mempertahankan hukum perjanjian itu adalah, karena mereka ingin memperbaiki integritas nasional untuk mempertahankan identitas mereka sebagai umat Allah, sebab dengan identitas itu mereka memiliki hak istimewa atas bangsa-bangsa lain (Dunn, 1994: 126).

Selanjutnya Dunn menyebut dua alasan lain yang menyebabkan kelompok orang Yahudi itu mengharuskan orang Kristen Galatia disunat. Pertama, hukum perjanjian itu telah diikat sedemikian kuat di antara orang Yahudi dalam pengertian sebagai identitas etnik yang menandai mereka sebagai umat pilihan Allah. Suatu identitas yang berbeda dari bangsa-bangsa lain. Kedua, ada keyakinan di kalangan kelompok Yahudi itu bahwa hukum perjanjian itu harus dilaksanakan oleh umat perjanjian (Dunn, 1994: 128).

Menurut pendapat saya, Sanders dan Dunn telah memberikan pandangan yang berharga, terutama mengenai hukum perjanjian, yang bagi orang Yahudi merupakan hukum yang mutlak. Sebab, Allah telah mengikat perjanjian dengan Abraham dan keturunannya dan Ia telah memberikan hukum Taurat agar mereka melaksanakannya, dan tanda perjanjian itu adalah sunat. Apalagi sesudah pembuangan, hukum Taurat menempati posisi yang sangat sentral dalam lingkungan Yudaisme. Memang persembahan korban terus berlangsung di Bait Allah tetapi upaya mempelajari dan memberlakukan hukum Taurat dan tradisinya dalam kehidupan sehari-hari menjadi fokus utama (Russel, 1986: 58). Dalam naskah-naskah rabbinik, sunat merupakan suatu keharusan bagi orang non-Yahudi yang ingin menjadi proselit Yahudi dan bergabung sebagai umat Allah (Yudit 14:10; 1 Macc. 1:5, dan Jub. 15:33,34). Seseorang yang ingin menjadi proselit Yahudi maka kepadanya diajukan beberapa pertanyaan. Pertama, mengenai alasan mengapa ia ingin menjadi proselit Yahudi, kemudian apakah ia tahu Israel adalah bangsa yang dianiaya, ditindas, dan dibenci. Jika calon proselit itu menjawab: "Saya tahu, dan saya menerimanya". Ia juga dilarang untuk 
makan daging binatang yang haram dan merayakan hari sabat. Jika orang itu menjawab: "Ya, saya menerima", maka ia diterima dan disunat. Jika sunat itu tidak lengkap sebagaimana seharusnya maka ia disunat untuk kedua kalinya segera setelah sunat yang pertama itu sembuh. Kemudian ia dibaptis (Sandmel, 1978: 232, 233).

Konsekuensinya, setiap orang yang ingin menggabungkan diri dengan orang Yahudi sebagai proselit maka mereka harus disunat dan wajib belajar serta melaksanakan hukum Taurat dan hidup menurut halakha sebagai way of life dari orang Yahudi. Mereka yang tidak menerima hukum Taurat dan tradisinya akan ditolak (bYeb. 47a-b). Rabbi Jose, anak dari Rabbi Yudah mengatakan bahwa sekalipun calon proselit itu menolak hanya salah satu dari aturan tambahan rabinik, ia akan dinyatakan diskualifikasi (Schiffman, 1981: 124). Flavius Josephus juga mengungkapkan persyaratan penerimaan seseorang menjadi proselit Yahudi, bahwa mereka wajib menerima dan melaksanakan hukum Taurat sebagai bagian dari proses penerimaan mereka sebagai proselit Yahudi (Ant. XX.34-38).

Pada masa pemerintahan Antiochus IV Epifanes, ketika Helenisasi digalakkan maka ada larangan terhadap tradisi Yahudi, termasuk sunat (1 Macc. 1:60-64). Pelarangan itu menimbulkan pemberontakan oleh keluarga Makabi. Pertanyaan yang timbul adalah apakah karena pelarangan itu maka sunat dan tradisi Yahudi lainnya dihapus? Schiffman (1981: 126) dan Martin Hengel (1974: 305, 306) secara konklusif menyatakan bahwa di kalangan orang-orang non-Yahudi, pelaksanaan sunat memang menurun. Tetapi sunat tetap dilaksanakan di kalangan orang Yahudi sebagai tanda yang membedakan mereka dari orang non-Yahudi. Maka bagi mereka yang yang mau menjadi proselit Yahudi, sunat menjadi ujian ketulusan dan pengabdian. Orang yang tidak disunat, tidak dipandang sebagai orang Yahudi (Schiffman, 1981: 127). Persyaratan ini dipegang teguh oleh kelompok orang Yahudi yang legalistik. Kelompok ini menjadi sangat dominan dalam masyarakat Yahudi terutama sesudah tahun 70 AD. Mereka sangat kuat mempertahankan sunat dan hukum Taurat sebagai syarat bagi orang non-Yahudi yang masuk menjadi proselit Yahudi. Itulah sebabnya, di mata mereka, upaya menentang sunat dan pelaksanaan hukum Taurat seperti yang dilakukan oleh Paulus, dipandang sebagai suatu pengkhianatan terhadap Yudaisme (Hengel, 1974: 307, 308).

Ketika kekristenan lahir di Yerusalem maka anggota jemaat pertama yang percaya kepada Yesus dan dibaptis adalah orang-orang Yahudi, termasuk orang Yahudi legalis ini. Keberadaan mereka dalam jemaat Kristen terbukti dalam laporan Lukas, bahwa di antara orang-orang Yahudi yang menjadi Kristen itu terdapat beberapa orang Farisi yang sangat mempertahankan sunat dan hukum Taurat sebagai syarat mutlak bagi setiap orang non-Yahudi yang menjadi Kristen (Kis. 
15:5). Penganut pandangan para Farisi atau lebih tepat orang Kristen Yahudi legalis ini datang ke Galatia dan mendesak anggota jemaat agar mereka disunat dan melaksanakan hukum Taurat.

Pengajaran dan desakan kelompok orang Kristen Yahudi itu secara tidak langsung telah menempatkan orang Kristen Galatia di persimpangan jalan. Pertanyaan yang timbul adalah: Apakah mereka harus menerima perjanjian sunat sesuai dengan desakan dari orang Kristen Yahudi itu dan melaksanakan hukum Taurat, supaya mereka menjadi anak-anak Abraham secara penuh? Ataukah mereka tetap setia kepada pemberitaan Paulus bahwa oleh iman, mereka telah dibenarkan dan telah menjadi anak-anak Abraham?

\section{RESPONS PAULUS TERHADAP DESAKAN AGAR ORANG KRISTEN GALATIA DISUNAT}

\section{1. “Injil Lain" (Heteron Euanggelion)}

Segera sesudah Paulus menyampaikan salam kepada jemaat di Galatia (Gal. 1:1-5) maka ia langsung menyatakan keheranannya terhadap sikap jemaat itu yang cepat berbalik dari ajaran Paulus (Gal. 1:6). Karena jemaat itu telah mengikuti suatu "injil lain". Pertanyaan yang timbul adalah: Apa yang Paulus maksudkan dengan "injil lain" itu? Pada umumnya, para penafsir ${ }^{2}$ berpendapat bahwa "injil lain” yang Paulus maksudkan adalah "injil yang disertai dengan kewajiban melaksanakan sunat dan hukum Taurat" yang oleh Paulus dipandang sebagai "kuk perhambaan" (Gal. 5:1).

Saya sependapat dengan pandangan para penafsir tentang “injil lain” yang Paulus sebutkan dalam Galatia 1:6,7 itu, yakni Injil yang disertai dengan kewajiban melaksanakan sunat dan hukum Taurat. ${ }^{3}$ Karena perdebatan yang hangat antara Paulus dan saudara-saudara palsu yang tercermin dalam surat Galatia adalah sunat dan hukum Taurat (Gal. 1:6-10; 2:3-5, 15-21; 3:1-29; 4:1-31; $5: 6-14 ; 6: 11-15)$.

"Injil lain" itu menjadi kuk perhambaan bagi orang-orang Galatia karena menghambat kebebasan mereka. Paulus menegaskan bahwa "injil lain" itu sesungguhnya bukan injil. Sebab orang yang memberitakan injil itu hanya mengacaukan, dan menghasut serta memutarbalikkan Injil Kristus (Gal. 1:7; 5:10,12). Sebaliknya Injil yang Paulus beritakan adalah Injil tanpa sunat (Lüdeman, 1980: 45; Betz, 1979: 49). Injil yang ia beritakan itu ia peroleh bukan dari manusia melainkan oleh penyataan Yesus Kristus (Gal. 1:12). Itu berarti bahwa Injil yang Paulus beritakan itu memiliki wibawa ilahi yang ia terima secara pribadi langsung dari Kristus. Injil ini berbeda dengan Injil yang diberitakan oleh lawan-lawan Paulus itu. Injil yang Paulus beritakan menekankan 
iman, sedangkan injil yang diberitakan lawan-lawannya menekankan sunat dan hukum Taurat. Oleh sebab itu Paulus menolak "injil lain” itu.

\section{Menolak Sunat sebagai Tanda Perjanjian}

Penolakan Paulus mengenai sunat yang diwajibkan oleh kelompok orang Kristen Yahudi itu, dimulai dari Abraham, karena lawan-lawannya memakai perjanjian Allah dengan Abraham sebagai dasar argumentasi mereka. Jawaban Paulus terhadap lawan-lawannya cukup cerdik. Ia tidak memulai dari Kejadian 17, sebab di sana hanya ditekankan sunat. Dengan memakai LXX, Paulus bertolak dari Kejadian 15 yang menekankan iman Abraham. Paulus mengatakan, "Secara itu jugalah Abraham percaya kepada Allah, maka Allah memperhitungkan hal itu kepadanya sebagai kebenaran" (Gal. 3:6 band. Kej. 15:6). Paulus memulai argumentasinya dengan ungkapan: Ka $\theta \grave{\omega} \varsigma^{4}$

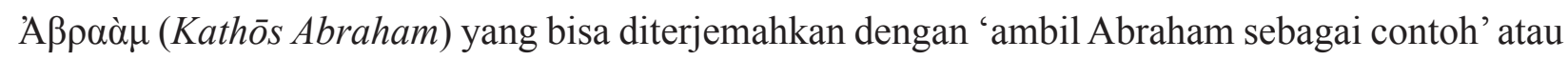
'lihat pada Abraham'. Dengan ungkapan ini, Paulus menampilkan iman Abraham sebagai contoh. Iman itulah yang menjadi dasar penerimaan perjanjian itu.

Pandangan Paulus itu didasarkan pada Kejadian 15:6. Dari kutipan itu, Paulus menegaskan bahwa "iman Abraham itu diperhitungkan kepadanya sebagai kebenaran" (Gal. 3:6). Dunn mengungkapkan bahwa kalimat "memperhitungkan hal itu kepadanya sebagai kebenaran" dipahami di dalam tradisi ${ }^{5}$ Israel sebagai petunjuk mengenai kesetiaan mereka kepada perjanjian yang Allah perhitungkan sebagai kebenaran. Sementara Rasul Paulus mengaitkan tradisi Israel ini dengan iman Abraham. Iman Abraham itu menjadi contoh pembenaran oleh Allah (Gal. 3:7). ${ }^{6}$

Maka mereka yang hidup dari iman itulah yang memperoleh pembenaran. Iman itu memampukan setiap orang yang menerimanya memiliki komitmen untuk mempercayakan diri sepenuhnya kepada Allah (Longenecker, 1990: 113). Karena iman itu adalah suatu anugerah maka iman itu tidak bisa dibayar dengan apa pun. Menurut Paulus orang-orang yang memiliki iman inilah

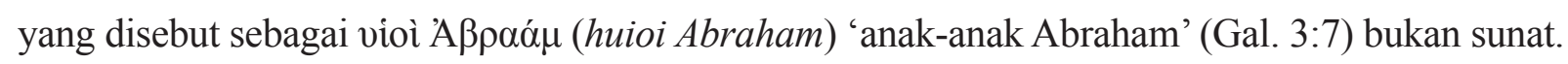

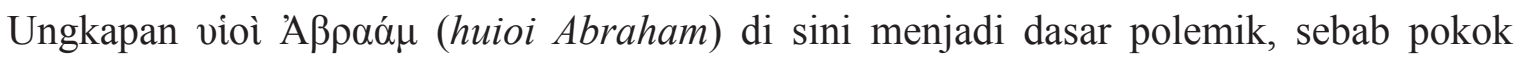
perdebatan itu berkaitan dengan sunat yang menjadi tanda status sosial sebagai anak-anak

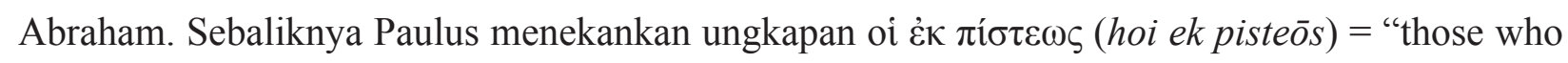
rely on faith" (Longenecker, 1990: 114), yakni mereka yang bersandar pada iman. Lebih jauh Paulus mengutip Kejadian 12:3 untuk menunjukkan bahwa janji Allah kepada Abraham itu tidak hanya bagi orang Israel, tetapi untuk semua bangsa, termasuk orang Kristen berlatar belakang nonYahudi di Galatia (bdk. Gal. 3:8) (Witherington III, 1998a: 227, 228; Cole, 1989: 135). Perjanjian Allah dengan Abraham itu dilakukan terlebih dahulu (Kej. 15) kemudian baru disusul dengan 
sunat sebagai tanda perjanjian (Kej. 17). Sedangkan hukum Taurat itu baru muncul lebih kemudian lagi, yakni empat ratus tiga puluh tahun (Ellis, 1982: 184, 185; Cole, 1989: 147). Dalam perkataan lain, iman Abraham telah diperhitungkan sebagai kebenaran sebelum sunat diperintahkan oleh Allah (Dunn, 1998: 376). Oleh karena itu, Paulus bisa mengatakan bersunat atau tidak bersunat tidak ada arti, hanya iman yang bekerja oleh kasih (Gal. 5:6; 6:15).

Dengan demikian kiranya jelas bahwa Paulus menolak sunat diberlakukan bagi orang-orang Kristen di Galatia karena, menurut Paulus, pembenaran itu diperoleh bukan karena sunat melainkan oleh iman. Iman Abraham itu diperhitungkan kepadanya sebagai kebenaran. Maka semua orang, termasuk orang non-Yahudi, yang mewarisi iman Abraham itu, adalah anak-anak Abraham. Sebab Allah telah berjanji kepada Abraham bahwa "olehmu semua bangsa beroleh berkat".

\section{Menolak Pembanggaan Diri Melaksanakan Taurat}

Penolakan Paulus terhadap ajaran orang Kristen Yahudi yang datang ke Galatia itu tidak berhenti pada sunat saja. Ia juga menyatakan penolakannya terhadap Taurat sebab lawan-lawannya itu membanggakan diri sebagai orang-orang yang dengan sempurna melaksanakan hukum Taurat. Paulus mengatakan, "Karena semua orang yang hidup dari pekerjaan-pekerjaan hukum Taurat berada di bawah kutuk" (Gal. 3:10). Demi mendukung penegasannya ini, ia mengutip Ulangan 27:26, "Terkutuklah orang yang tidak setia melakukan segala sesuatu yang tertulis dalam kitab hukum Taurat." Dengan kutipan ini, Paulus secara umum mengingatkan orang Yahudi agar mereka membebaskan diri dari kutuk hukum Taurat (bdk. Gal. 4:5). Sebab orang yang menempatkan diri di bawah hukum Taurat, dengan maksud untuk mengambil bagian dalam berkat Abraham, terancam oleh kutuk hukum Taurat itu. ${ }^{7}$ Sebab hukum Taurat menuntut ketaatan yang sempurna, sementara tidak ada seorang pun yang mampu melaksanakan semua tuntutan hukum Taurat itu, sebab semua orang berada di bawah kutuk dosa (Dunn, 1998: 361), dan tidak ada seorang pun dibenarkan di hadapan Allah karena melakukan hukum Taurat.

Paulus mengutip lagi Habakuk 2:4, untuk memberikan pendasaran terhadap pandangannya ini, “Orang yang benar akan hidup oleh iman" (Gal. 3:11). Dengan kutipan dari kitab Habakuk

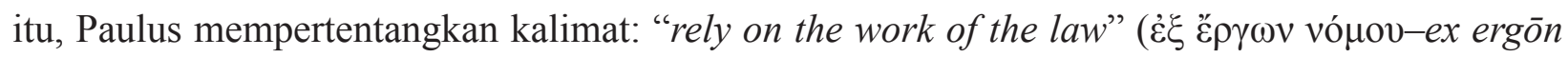

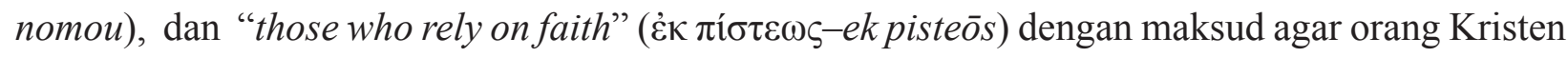
di Galatia melihat secara jelas orang yang hidup dari pekerjaan hukum Taurat dan mereka yang hidup oleh iman (Longenecker, 1990: 116; lih. juga Matera, 1992: 124). Dengan kutipan itu juga, ia membuktikan bahwa pembenaran oleh iman tidak hanya dalam Kejadian 15:6. Nabi Habakuk pun menegaskan pembenaran yang demikian (Ellis, 1982: 186). Lebih jauh, Paulus mengatakan 
kepada orang Kristen di Galatia bahwa sama seperti Abraham dibenarkan oleh iman, demikian pula mereka dibenarkan oleh iman kepada Allah oleh Yesus Kristus.

Memang Paulus memahami bahwa setiap orang yang melakukan hukum Taurat akan hidup oleh hukum Taurat. Pemahaman itu nyata dalam Imamat 18:5. Dalam teks itu penulis kitab Imamat menjanjikan hidup bagi mereka yang melaksanakan hukum Taurat dengan sempurna (bdk. Gal. 3:12). Persoalannya adalah: Siapakah yang dapat melaksanakan seluruh hukum Taurat itu? Menurut Paulus tidak ada seorang pun yang mampu melakukan seluruh hukum Taurat itu dengan sempurna, sehingga tidak pernah ada seorang pun beroleh hidup dari hukum Taurat itu (3:21) (Matera, 1992: 153). Ketidakmampuan manusia melakukan hukum Taurat itu menyebabkan mereka yang mengandalkan hukum Taurat berada di bawah ancaman kutuk Allah, teristimewa orang Yahudi. Dalam perkataan lain, Paulus hendak mengingatkan lawan-lawannya, termasuk orang Kristen di Galatia bahwa mereka yang melakukan hukum Taurat berada di bawah ancaman kutuk hukum itu (Hays, 2000: 258).

Demi pembebasan dari ancaman kutuk hukum Taurat itu maka Paulus menawarkan jalan keluar. Bahwa oleh kematian Kristus di atas kayu kutuk itu maka kutuk yang mengancam itu telah dibatalkan. Kristus telah "membebaskan"s kita dari kutuk hukum Taurat dengan menjadi kutuk karena kita, melalui penyaliban-Nya di atas kayu salib. Paulus mengutip Ulangan 21:23 untuk meyakinkan lawan-lawannya bahwa Allah mengutus Anak-Nya yang lahir dari seorang perempuan dan takluk kepada hukum Taurat dengan maksud agar Ia menebus mereka yang takluk kepada hukum Taurat supaya kita diterima menjadi anak (Gal. 4:4-5) (Dunn, 1998: 210). Maka orang yang beriman kepada Yesus telah dibebaskan dari kutuk itu. Oleh karena itu, Paulus bisa berkata, "Sebab aku telah mati oleh hukum Taurat untuk hukum Taurat supaya aku hidup untuk Allah. Aku telah disalibkan dengan Kristus" (Gal. 2:19) (Ellis, 1982: 186).

Mengomentari pandangan Paulus tentang hukum Taurat ini, E.P. Sanders, dalam bukunya, Paul, the Law, and the Jewish People, mengemukakan bahwa Paulus telah memutuskan hubungan dengan Taurat sehingga menimbulkan persoalan. Di samping itu, jawabannya beragam jika dibadingkan satu dengan yang lainnya. Bahkan jawaban Paulus itu, lanjut Sanders, secara keseluruhan tidak membentuk suatu gagasan yang logis. Jadi, menurut Sanders, Paulus, sebagai seorang Yahudi, tidak menyampaikan alasan yang real (Sanders, 1983: 3, 4).

Terhadap pandangan Sanders ini, James D.G. Dunn menyampaikan kritik. Menurut Dunn, penjelasan Sanders itu sangat tidak memuaskan. Ia telah gagal mengangkat bagian terdalam dari situasi sosial yang Paulus hadapi. Ia juga gagal menangkap fungsi sosial dari Taurat pada masa Paulus dan bagaimana hal itu memengaruhi kedua isu yang mempertentangkan Paulus 
dengan lawan-lawannya itu (Dunn, 1990: 215, 216). Menurut Dunn, ada dua kata kunci yang mesti didalami untuk memahami situasi sosiologis pada masa Paulus, yakni identitas dan batas (boundery). Dengan mengutip Mary Douglas, Dunn mengemukakan bahwa secara sosiologis, jika satu kelompok dalam masyarakat merasa identitasnya terancam maka ada kecenderungan untuk mereka menentukan batas-batasnya dengan maksud melindungi diri.

Situasi sosial seperti ini terjadi pada masa Paulus. Sebagai contoh, lanjut Dunn, sesudah periode pembuangan, yakni sekitar periode Makkabi, orang Israel, sebagai minoritas yang ditekan, dihadapkan pada ancaman asimilasi oleh bangsa Syria, tetapi banyak dari orang Israel yang tetap teguh melaksanakan hukum perjanjian itu. Mereka tidak mau memakan makanan yang najis. Di sini, identitas dan batas (boundery) itu menjadi penanda yang jelas bagi identitas diri mereka yang berbeda dari bangsa-bangsa lain.

Demikian juga dalam dua isu utama yang Paulus hadapi di Galatia, yakni sunat dan hukum Taurat termasuk aturan mengenai makanan sebagai penanda bagi orang Yahudi yang adalah umat pilihan Allah. Benar, bahwa bagi orang Yahudi yang saleh, ketaatan penuh kepada hukum perjanjian yang tertulis dalam Taurat merupakan hal yang utama. Tetapi jika dilihat dari perspektif sosiologis anthropologis maka yang menjadi taruhan adalah identitas umat itu sendiri. Mereka tidak mau bercampur dengan bangsa lain, dengan maksud agar mereka tidak meninggalkan jalan yang ditempuh oleh para bapa leluhur mereka. Dengan demikian, lanjut Dunn, Taurat merupakan aspek yang tidak bisa dipisahkan dari identitas Israel, baik sebagai bangsa maupun sebagai agama (Dunn, 1990: 217-218).

Menurut pendapat saya, pandangan yang dikemukakan Sanders bahwa timbulnya persoalan itu karena Paulus memutuskan hubungan dengan Taurat, tidak seluruhnya bisa diterima. Benar, bahwa Paulus menolak sunat yang diberlakukan kepada orang Kristen non-Yahudi di Galatia. Karena menurut Paulus, sunat adalah tradisi untuk orang Yahudi. Maka orang Kristen non-Yahudi tidak perlu mengikuti tradisi Yahudi itu. Namun, Paulus masih memandang Taurat sebagai hukum Allah (Rm. 7:22). Taurat itu juga kudus, benar, dan baik (Rm. 7:12,16). Paulus juga memandang hukum Taurat sebagai anugerah, yang Allah berikan kepada Israel (Rm. 9:4) (Segal, 1991: 11, 12) dan memiliki fungsi sebagai penuntun (paedagogos) dalam kehidupan umat (Gal. 3:24). Orang yang melakukan hukum Taurat akan hidup olehnya (Rm. 10:5; Gal. 3:12). Nyata bahwa, Paulus masih memandang hukum Taurat sebagai sesuatu yang positif. Yang Paulus tolak adalah pembanggaan diri orang Yahudi bahwa mereka mampu melaksanakan semua hukum Taurat itu.

Pandangan Dunn, menurut hemat saya, lebih konklusif. Sebab, ia secara meyakinkan mengungkap fungsi sosial dari hukum Taurat sebagai penanda batas antara orang Yahudi dan orang 
bukan Yahudi. Fungsi sosial itu yang mendorong kelompok orang Yahudi yang datang ke Galatia mewajibkan orang Kristen non-Yahudi disunat dan mereka harus melaksanakan hukum Taurat. Namun Paulus menolak pandangan itu, sebab menurut Paulus, orang dibenarkan bukan oleh sunat dan melaksanakan semua aturan hukum Taurat melainkan oleh iman. Iman itu memungkinkan mereka mengambil bagian dalam hubungan perjanjian dengan Abraham dan mewarisi perjanjian itu, serta memperoleh berkat Allah yang sejak semula disediakan juga bagi dunia bangsa-bangsa (Gal. 3:8; bdk. Kej. 12:3; 18:18). Paulus menyebut janji berkat itu sebagai proklamasi Injil dan menunjukkan bahwa penerimaan orang non-Yahudi oleh karena iman. Iman itu adalah inti Injil. Paulus menyimpulkan bahwa mereka yang hidup dari iman akan diberkati bersama-sama dengan Abraham (Gal. 3:9).

Dengan demikian kiranya jelas bahwa menurut orang Yahudi, Abraham dibenarkan karena melakukan hukum Taurat. Tetapi Paulus membantah pandangan itu berdasarkan Kejadian 15:6 yang ia kutip dalam Galatia 3:6, bahwa pembenaran itu diberikan karena iman, bukan karena melakukan hukum Taurat. Hukum Taurat itu baru diberikan dikemudian hari. Menurut Paulus orang yang melaksanakan hukum Taurat itu berada di bawah kutuk sebab tidak ada seorang pun yang mampu melaksanakan semua aturan hukum Taurat itu. Maka untuk membebaskan diri dari kutuk itu, Paulus menawarkan iman kepada Kristus yang tersalib di atas kayu kutuk itu. Sebab melalui penyalibanNya di atas kayu kutuk itu, Ia telah menanggung kutuk itu. Maka orang yang memiliki iman kepada Kristus, dibebaskan dari kutuk itu. Dalam kaitan ini, orang-orang Kristen non-Yahudi di Galatia itu telah memiliki iman kepada Kristus sehingga mereka telah dimerdekakan oleh Kristus.

\section{PAULUS: SEORANG PENGINJIL YANG TERBUKA BAGI ORANG NON-YAHUDI}

Pertanyaan yang timbul adalah: Mengapa Paulus begitu kuat menekankan iman sebagai dasar pembenaran dan menjamin status seseorang menjadi anak Abraham? Padahal ia adalah seorang Farisi yang dahulu mengajar orang Yahudi agar mereka disunat dan melaksanakan semua ketentuan hukum Taurat itu dengan sempurna.

Menjawab pertanyaan itu, Alan F. Segal, dalam penelitiannya mengungkap secara jelas sikap Paulus setelah ia menjadi Kristen. Menurut Segal, jika Paulus dibandingkan dengan Yakobus dan Petrus maka mereka memiliki posisi yang berbeda. Yakobus masih menerima tradisi sunat dan hukum Taurat, sementara Petrus lebih moderat. Sedangkan Paulus lebih terbuka kepada orang-orang non-Yahudi dan menolak sunat dikenakan kepada orang Kristen non-Yahudi (Segal, 1991: 12). 
Menurut pendapat saya, Segal telah memberikan pandangan yang meyakinkan tentang alasan mengapa Paulus menekankan iman sebagai dasar pembenaran dan jaminan bagi seseorang menjadi anak Abraham. Dalam Filipi 3:4b-8 Paulus memaparkan kehidupannya dahulu yang waktu itu ia banggakan. Secara lahiriah ia disunat pada hari kedelapan, ia adalah orang Ibrani asli dan keturunan Abraham dari suku Benyamin (bdk. Rm. 11:1). Ia adalah seorang Farisi yang belajar dari Gamaliel dan taat melakukan hukum Taurat. Bahkan sebagai seorang rabi Yahudi, ia mengajar orang-orang Yahudi agar mereka taat kepada seluruh tuntutan hukum itu dan demi membela hukum Taurat itu ia menganiaya para pengikut Yesus. Namun, ketika ia menjadi Kristen, apa yang dahulu merupakan keuntungan baginya, sekarang ia anggap rugi karena Kristus. Oleh karena Kristus, maka ia telah melepaskan semuanya itu dan dianggapnya sebagai sampah (Malina dan Neyrey, 1996: 204, 205). Paulus lebih menekankan iman daripada sunat dan pembanggaan melaksanakan hukum Taurat (Gal. 5:6; 6:15).

Pandangan Paulus ini mencerminkan suatu titik balik dalam hidupnya setelah ia menjadi Kristen (Kis. 9:1-18). Pengalaman itu diungkapkan Paulus dalam suratnya kepada jemaat di Galatia (Gal. 1:11-24). Dalam ungkapan itu, Paulus secara tegas menyatakan bahwa dahulu ia adalah seorang penganiaya jemaat, tetapi sekarang ia menjadi seorang pemberita iman kepada Kristus (ay. 23). Iman itulah yang menjadi dasar argumentasi Paulus dalam melawan pandangan Yahudi mengenai kriteria menjadi keturunan Abraham.

Dengan demikian, setelah Paulus menjadi Kristen maka telah terjadi suatu pergeseran penekanan pada kriteria bagi seseorang beroleh keselamatan, yaitu pergeseran dari hubungan darah atau hubungan genealogis dengan Abraham kepada iman. Maka ia sangat terbuka dalam penerimaan orang bukan Yahudi menjadi orang Kristen dengan memberikan tekanan pada iman. Iman itulah yang memungkinkan seseorang beroleh selamat. Sikap keterbukaan dan penekanan pada iman itu nyata dari penolakan Paulus terhadap pemberitaan beberapa orang dari Yudea yang mengajarkan bahwa orang Kristen di Antiokhia harus disunat untuk memperoleh selamat. Penolakan itu menimbulkan perdebatan sehingga soal itu dibawa ke sidang di Yerusalem.

\section{KEPUTUSAN SIDANG DI YERUSALEM}

Laporan mengenai sidang di Yerusalem kita jumpai dalam Galatia 2:1-10 dan Kisah Para Rasul 15:1-21. Laporan dalam Galatia 2:1-10 langsung disampaikan oleh Paulus sebagai saksi mata yang hadir dalam sidang di Yerusalem itu. Sementara laporan dalam Kisah Para Rasul 15:1-21, ditulis oleh Lukas yang kemungkinan diperoleh dari Paulus. Kedua sumber ini akan ditelusuri secara bersama. 
Menurut Galatia 2:1,2 Paulus pergi ke Yerusalem berdasarkan suatu penyataan agar ia membentangkan Injil yang ia beritakan di antara bangsa-bangsa bukan Yahudi kepada para soko guru jemaat di Yerusalem. Kepergiannya itu bersama dengan Barnabas seorang Yahudi yang berasal dari Siprus ${ }^{9}$ dan Titus seorang Yunani (Gal. 2:3). ${ }^{10}$ Sementara menurut Kisah Para Rasul 15:1, sidang itu dilaksanakan karena, "Beberapa orang datang dari Yudea ke Antiokhia dan mengajarkan kepada saudara-saudara di situ: 'Jikalau kamu tidak disunat menurut adat istiadat yang diwariskan oleh Musa, kamu tidak dapat diselamatkan."” Pengajaran itu didukung oleh orang-orang dari golongan Farisi di Yerusalem, yang telah menjadi Kristen, bahwa orang-orang bukan Yahudi yang menjadi Kristen harus disunat dan diwajibkan untuk menuruti hukum Musa (Kis. 15:5). Mereka menghendaki agar orang bukan Yahudi harus menjadi proselit dengan cara melaksanakan sunat dan menaati hukum Musa (Sanders, 1987: 266; Marshall, 1980: 249). Tetapi Paulus dan Barnabas menentang ajaran itu (Kis. 15:2). Menurut Galatia 2:4, Paulus mengakui bahwa ada desakan dari saudara-saudara palsu yang menyusup masuk untuk menghadang kebebasan orang Kristen nonYahudi. Namun Paulus menyatakan bahwa sesaat pun ia tidak tunduk kepada desakan saudarasaudara palsu itu. Dengan demikian, baik tulisan Paulus dalam Galatia 2 maupun laporan dalam Kisah Para Rasul 15, menekankan persoalan krusial antara Paulus dan saudara-saudara palsu itu, yakni sunat.

Persoalan krusial ini dibawa dalam sidang para penatua dan para rasul di Yerusalem. Menurut laporan dalam Kisah Para Rasul, dalam sidang itu, Petrus mengemukakan bahwa oleh pemberitaan Injil maka bangsa-bangsa lain telah percaya dan mereka juga diberi Roh Kudus sama seperti kepada rasul-rasul itu. Ternyata sesudah Allah menyucikan hati orang-orang bukan Yahudi oleh iman, maka Allah sama sekali tidak mengadakan pembedaan antara orang bukan Yahudi dan rasul-rasul serta para tua-tua yang mengikuti sidang itu. Pernyataan Petrus ini didasarkan pada pengalamannya sendiri dalam kisah Kornelius dan keluarganya yang menerima Roh Kudus berdasarkan iman semata (Kis. 10:47; 11:17) (Neil, 1973: 171).

Dalam pernyataan ini Petrus menunjuk kepada Allah sebagai Dia yang mengetahui hati semua orang lalu Petrus menarik kesimpulan bahwa pemberian Roh Kudus kepada orang bukan Yahudi itu terjadi karena Allah telah menyucikan hati mereka dari dosa. Dengan cara yang sama Ia juga menyucikan hati orang-orang Yahudi. Jadi, yang menjadi persoalan di sini adalah penyucian hati. Sementara perbuatan legalistik yang lahiriah seperti sunat bukanlah soal yang penting. Maka upaya untuk memaksakan sunat dan hukum Taurat kepada orang bukan Yahudi merupakan suatu cobaan terhadap Allah. Dengan demikian, persoalan di sini bukan pada hukum Taurat, melainkan pada ketidakmampuan manusia melaksanakannya (Marshall, 1980: 249, 250). 
Bertolak dari kenyataan itu, menurut laporan dalam Kisah Para Rasul, Petrus mengajukan pertanyaan kepada peserta sidang itu, "Mengapa kamu mencobai Allah dengan meletakkan pada tengkuk murid-murid itu suatu kuk, yang tidak dapat dipikul, baik oleh nenek moyang kita maupun oleh kita sendiri?" (Kis. 15:8-10). Di samping itu, Paulus dan Barnabas juga diberikan kesempatan untuk menceritakan segala tanda mukjizat yang dilakukan Allah di tengah bangsa-bangsa lain (Kis. 15:12). Merespons pernyataan Petrus dan pengalaman Paulus dan Barnabas, maka setelah membaca dari Amos 9:11-12 (band. Kis. 15:16-18), Yakobus mengambil keputusan.

Keputusannya adalah: "tidak boleh menimbulkan kesulitan bagi mereka dari bangsa-bangsa lain yang berbalik kepada Allah, tetapi kita harus menulis surat kepada mereka supaya mereka menjauhkan diri dari makanan yang telah dicemarkan berhala-berhala, dari percabulan, dari daging binatang mati dicekik dan dari darah" (Kis. 15:19,20). Keputusan itu diterima oleh peserta sidang di Yerusalem (Sanders, 1987: 267, 268; Marshall, 1980: 253). Keputusan itu disampaikan juga kepada jemaat di Antiokhia sebagai keputusan Roh Kudus dan keputusan para rasul dan penatua (Kis. 15:28,29). Dalam keputusan ini sunat tidak diwajibkan bagi orang-orang bukan Yahudi.

Sementara menurut versi surat Galatia keputusan yang Paulus sebutkan adalah pembagian misi secara etnografis. Paulus ditugaskan untuk memberitakan Injil kepada orang-orang yang tidak bersunat, yaitu bangsa-bangsa bukan Yahudi, sedangkan Petrus untuk mereka yang bersunat, yakni orang-orang Yahudi. Keputusan itu ditandai dengan jabatan tangan oleh Yakobus, Petrus, dan Yohanes dengan Paulus (Gal. 2:9).

Meskipun ada perbedaan versi keputusan antara kedua laporan ini, namun yang pasti adalah bahwa sunat tidak diwajibkan bagi orang non-Yahudi. Memang dalam versi laporan yang Paulus sampaikan dalam surat Galatia, ia menyebutkan bahwa ada saudara-saudara palsu yang menyelundup masuk dan memaksakan sunat tetapi Paulus menegaskan bahwa sesaat pun ia tidak mundur (Gal. 2:4,5). Dalam perkataan lain, sekalipun ada desakan supaya sunat diwajibkan tetapi Paulus mempertahankan pandangannya bahwa sunat tidak perlu dipaksakan bagi orang non-Yahudi.

Tampaknya keputusan itu tidak begitu saja diterima oleh semua kelompok Kristen di Yerusalem, terutama kelompok Yahudi legalistik yang telah menjadi Kristen itu. ${ }^{11}$ Kelompok ini masih memegang teguh sunat dan hukum Taurat serta tradisi-tradisinya sebagai suatu kebanggaan dan hak istimewa (Witherington III, 1998b: 454). Kelompok inilah yang datang ke Galatia dan mewajibkan orang Kristen menjadi proselit dengan melaksanakan sunat. Namun Rasul Paulus memiliki dasar hukum yang kuat juga, yakni hasil keputusan sidang para rasul dan tua-tua di Yerusalem bahwa tidak boleh menimbulkan kesulitan bagi mereka dari bangsa-bangsa lain yang berbalik kepada Allah. 
Dari catatan ini, kiranya jelas bahwa dalam sidang para rasul dan tua-tua di Yerusalem, sunat sebagai persoalan krusial tidak diwajibkan bagi orang-orang dari bangsa-bangsa bukan Yahudi. Aspek yang ditekankan adalah iman (Kis. 15:9) dan memelihara kekudusan (Kis. 15:20,21).

\section{KESIMPULAN}

Berdasarkan uraian di atas maka di bawah ini akan diambil beberapa kesimpulan. Pertama, desakan orang-orang Kristen Yahudi legalis, agar orang Kristen di Galatia harus disunat menimbulkan kebingungan. Mereka bingung karena pada satu pihak, oleh pemberitaan Injil yang Paulus lakukan, mereka telah percaya kepada Kristus dan dibaptis. Tetapi di pihak lain, orang-orang Kristen Yahudi legalis yang datang ke Galatia itu mengajarkan bahwa orang Kristen di Galatia harus disunat supaya beroleh status sebagai anak-anak Abraham dan beroleh selamat. Sebab sunat merupakan tanda perjanjian sejak Abraham dan diwajibkan bagi semua orang non-Yahudi.

Kedua, pandangan orang Kristen Yahudi legalis itu dilawan oleh Paulus. Menurut Paulus seseorang yang masuk Kristen tidak perlu menjadi proselit Yahudi terlebih dahulu melalui sunat. Yang penting, menurut Paulus adalah iman. Oleh sebab itu, orang Kristen yang telah mewarisi iman itu tidak perlu disunat. Sebab sunat merupakan tradisi Yahudi, sehingga tidak perlu diberlakukan bagi orang bukan Yahudi.

Ketiga, penolakan Paulus terhadap sunat bukan tanpa alasan dan bukan pula mengkhianati tradisi sunat dalam Perjanjian Lama. Sebab dalam keputusan sidang di Yerusalem, sunat sama sekali tidak diwajibkan bagi mereka yang berasal dari bangsa-bangsa bukan Yahudi. Sunat sebagai suatu tradisi Yahudi, bisa saja diberlakukan di kalangan orang Yahudi. Tetapi sunat tidak perlu diberlakukan bagi orang bukan Yahudi. Sebab mereka telah menjadi anak Abraham oleh iman.

Keempat, ternyata keputusan itu tidak serta merta diterima oleh semua orang Kristen pada waktu itu, terutama kelompok legalistik yang telah menjadi Kristen itu. Mereka masih berpegang teguh kepada sunat dan hukum Taurat sebagai tradisi dari Abraham dan Musa yang tidak boleh diabaikan. Sebab, menurut mereka, sunat dan hukum Taurat itu menjadi pintu masuk bagi seseorang menjadi anak Abraham. Dua pandangan yang berbeda itulah yang menimbulkan debat teologis yang dibahas dalam sidang di Yerusalem. Salah satu keputusan sidang itu adalah tidak menimbulkan kesulitan termasuk sunat bagi orang bukan Yahudi menjadi Kristen. 


\section{Catatan}

${ }^{1}$ Setelah penghancuran kota Yerusalem, persembahan korban tidak lagi dituntut (Schiffman, 1981: 122).

2 Para penafsir itu adalah Hans Dieter Betz (1979: 48), J.J.W. Gunning (1975: 22), serta Daniel C. Arichea dan Eugene A. Nida (2011: 14).

${ }^{3}$ Ungkapan: injil lain (hetero euanggelion) terdapat juga dalam 2 Korintus 11:4. Dalam teks itu Paulus menentang lawan-lawannya yang memberitakan Yesus yang lain, roh yang lain, dan injil yang lain. Tetapi dalam konteks surat 2 Korintus, injil lain sebagaimana dimaksudkan oleh Paulus di Galatia, misalnya: sunat dan memelihara hari sabat, tidak dijumpai. Yang dijumpai di Korintus adalah kelompok orang Yahudi yang memiliki paham gnostik. Oleh sebab itu, tepat jika "injil lain" yang Paulus maksudkan di 2 Korintus adalah ajaran gnostik yang menolak kemanusiaan Yesus (1 Kor. 12:3) (lih. Matin, 1986: 336).

${ }^{4}$ Kata Ka $\alpha \dot{\omega} \varsigma$ (Kathōs) biasanya dipakai sebagai rumusan pengantar yang digunakan dalam tulisan-tulisan Yunani dan PB untuk membuat satu perbandingan, misalnya "sama seperti". Dalam PB kata itu biasa juga digandeng dengan kata $\gamma \in \gamma \rho \alpha \pi \tau \alpha \iota$ (gegraptai) yang diterjemahkan dengan: 'as it is written' (Mat. 25:24; Mrk. 1:214:21; Luk. 2:23, dll. (lih. Longenecker, 1990: 112).

${ }^{5}$ Dalam Mazmur 106:30,31, Pinehas dipuji karena tindakan intervensinya yang krusial dan pemazmur menyisipkan kalimat: "dan hal itu diperhitungkan kepadanya sebagai kebenaran". Hal yang sama dalam Yobel 30:17, tindakan yang berani dari Simon dan Lewi dalam pembunuhan terhadap musuhnya telah diperhitungkan kepada mereka sebagai kebenaran (Dunn, 1998: 376).

${ }^{6}$ Pembenaran oleh Allah itu merupakan anugerah ilahi (Dunn, 1993: 377).

${ }^{7}$ Hukum yang dimaksudkan oleh Paulus di sini tidak hanya hukum Taurat tetapi hukum pada umumnya (lih. Witherington III, 1998a: 232, 233).

${ }^{8}$ Kata kerja yang Paulus pakai di sini adalah $\epsilon \xi \eta \gamma o p \alpha \sigma \epsilon \nu$ (exēgorasen) 'membebaskan'. Kata ini biasanya dipakai untuk pembebasan seorang budak. Ungkapan ini nanti Paulus pakai sebagai gambaran yang segera menyusul, yaitu bahwa hidup di bawah hukum Taurat adalah suatu bentuk perhambaan (Gal. 4:1-11, 21-5:1), namun penyaliban Kristus telah membebaskan orang yang berada di bawah ancaman kutuk hukum Taurat itu (lih. Hays, 2000: 160).

${ }_{9}$ Barnabas menjadi seorang Kristen dan mendukung gereja dengan menjual sebidang tanah. Ia menjadi mentor dari Paulus dan memperkenalkan dia kepada para rasul (Kis. 9:27). Ia pergi ke Antiokhia dan menjadi pemimpin di sana (Kis. 11:30). Sesudah perselisihan di Antiokhia Barnabas dan Paulus bekerja terpisah (Kis. 14:4) (Betz, 1979: 84).

${ }^{10}$ Titus masuk Kristen (Tit. 1:4) dan menjadi pengikut Paulus. Menurut 2 Korintus 2:13; 7:6,13,14; 8:6,16,23; 12:18; Titus menjadi koordinator pengumpulan persembahan bagi jemaat di Yerusalem. Menurut 2 Timotius 4:10, ia bekerja di Dalmatia dan Titus 1:5 menyebut dia di Kreta (lih. Betz, 1979: 84).

${ }^{11}$ Dikatakan demikian karena sudah sidang para rasul dan tua-tua di Yerusalem, hasil keputusan itu disampaikan kepada jemaat di Antiokia. Paulus dan Silas menyampaikan keputusan itu juga kepada jemaat di Galatia, tetapi sesudah Paulus dan Silas pergi, orang-orang Kristen Yahudi yang masih berpegang teguh pada sunat dan hukum Taurat itu datang ke Galatia dan mendesak jemaat untuk melaksanakan sunat (Groenen, 1984: 247-247; lih. juga Hakh, 2010: 174-177).

\section{DAFTAR PUSTAKA}

Arichea, Daniel C. dan Eugene A. Nida. 2011. Surat Paulus kepada Jemaat di Galatia, adaptasi dari: A Translators Handbook on Paul's Letter to the Galatians, Jakarta: Lembaga Alkitab Indonesia dan Yayasan Karunia Bakti Budaya Indonesia. 
Baird, William. 1988. "Abraham in the New Testament Tradition and the New Identity", Interpretation, 42.

Betz, Hans Dieter. 1979. Galatians, A Commentary on Paul's Letter to the Churches in Galatia, Philadelphia: Fortress Press.

Crossan, John Dominic dan Jonathan L. Reed. 2004. In Search of Paul, USA: Harper Collins Publisher.

Dunn, James D.G. 1990. Jesus, Paul and the Law, Studies in Mark and Galatians, Louisville Kentucky: Westminster/John Knox Press.

. 1994. "The Teology of Galatians: The Issue of Covenantal Nomism", Pauline Theology Vol. 1: Thessalonians, Philippians, Galatians, Philemon, Jouette M. Bassler (ed.), Minneapolis: Fortress Press.

. 1993. The Theology of Paul's Letter to Galatians: New Testament Theology, Cambridge: Cambridge University Press.

. 1998. The Theology of Paul the Apostle, Grand Rapids, Michigan/Cambridge, UK: William B. Eerdmans Pub. Co.

Cole, R. Alan. 1989. Tyndale New Testament Commentaries: Galatians, Leicester, England: InterVarsity Press/ Grand Rapids Michigan: W.B. Eerdmans Publ. Co.

Ellis, Peter F. 1982. Seven Pauline Letters, Collegeville, Minnesota: The Liturgical Press.

Groenen, C. 1984. Pengantar ke dalam Perjanian Baru, Yogyakarta: Kanisius.

Gunning, J.J.W. 1975. Tafsiran Surat Galatia, Jakarta: BPK Gunung Mulia.

Guthrie, Donald. 1973. The New Century Bible Commentary: Galatians, London: Marshall Morgan and Scott Publ. Ltd./Grand Rapids Michigan: WM. B. Eerdmans Publ. Co.

Hakh, Samuel Benyamin. 2010. Perjanjian Baru: Sejarah, Pengantar dan Pokok-pokok Teologisnya, Bandung: Bina Media Informasi.

Hays, Richard B. 2000. The Letter to Galatians: The New Interpreters Bible A Commentary in

Twelve Volumes, vol. XI. Nashville: Abingdon Press.

Hengel, Martin. 1974. Judaism and Hellenis, Studies in their Encounter in Palestine during the Early Hellenistic Period, London: SCM Press.

Ioanes Rakhmat. 2009. Menguak Kekristenan Yahudi Perdana, Jakarta: Jusufroni Center. 
Longenecker, Richard N. 1990. Word Biblical Commentary Vol. 41: Galatian, Dallas, Texas: Word Books Publisher.

Lüdeman, Gerd. 1984. Paul Apostle to the Gentiles: Studies in Chronology, London: SCM Press.

Malina, Bruce J. dan Jerome H. Neyrey. 1996. Portraits of Paul, An Archeology of Ancient Personality, Louisville, Kentucky: Westminster John Knox Press.

Matera, Frank J. 1992. Sacra Pagina, Galatians, Collegeville, Minnesota: The Liturgical Press.

Matin, Ralph P. 1986. Word Biblical Commentary: 2 Corinthians, Vol. 40, Waco, Texas: Word Books Publishers.

Marshall, I. Howard. 1980. Tyndale New Testament Commentaries, Acts, Leicester, England: Intervarsity Press, Grand Rapids, Michigan: W.B. Eerdmans Publ. Co.

Neil, William. 1973. The New Century Bible Commentary: The Acts of the Apostles, Grand Rapids: Wm. B. Eerdmans Publ. Co./London: Marshall, Morgan and Scott Publ. Ltd.

Russel, D.D. 1986. From Early Judaism to Early Church, London: SCM Press.

Sanders, E.P. 1983. Paul, the Law, and the Jewish People. Minneapolis: Fortress Press.

Sanders, Jack T. 1987. The Jews in Luke Acts, London: SCM Press Ltd.

Sandmel, Samuel. 1978. Judaism and Christian Beginings, New York: Oxford University Press.

Schiffman, Lawrence. 1981. "At the Crossroads: Tannaitic Perspective on the Jewish-Christian Schism, dalam Jewish and Christian Self-Definition, London: SCM Press.

Segal, Alan F. 1991. "Matthew's Jewish Voice”, dalam Social History of Matthean Community: Cross-Disciplinary Approaches, David L. Balch (ed.), Minneapolis: Fortress Press.

Spitz, Lewis W. 1960. Luter's Works, Vol. 34, Philadelphia: Muhlenberg Press.

Thielman, Frank. 2005. Theology of the New Testament, Grand Rapid Michigan: Zondervan.

Witherington III, Ben. 1998a. Grace in Galatia: A Commentary on St. Paul's Letter to the Galatians, Edinburgh: T\&T Clark.

. 1998b. The Acts of the Apostles: A Socio-Rhetorical Commentary, Grand Rapids Michigan: Wm B. Eerdmans Publ. Co./Carlisle: The Paternoster Press. 